\title{
A rare cause of gallbladder perforation: Burkitt's lymphoma
}

\author{
Musa Zorlu๑ \\ Department of Surgery, Private Active Hospital, Yalova, Turkey
}

DOI: $10.18621 /$ eurj.432284

\begin{abstract}
Although the perforation of gallbladder rarely occurs, it is a high-risk and life-threatening condition. High rates of mortality and morbidity are associated with late diagnosis. Burkitt's lymphoma is a disease, which starts in B-cells and develops with leukemia and extranodal involvement. Involvement of gallbladder wall is a very rare location of extranodal lymphomas. In this case, a 68-year-old woman with severe pain in the left arm referred to our outpatients' clinic where anti-HCV $(+)$, leukocytosis, elevated sedimentation rate, and thrombocytopenia were found in her initial tests. On the basis of these findings, further tests were performed and she was diagnosed with Burkitt's lymphoma. She had acute abdomen and gallbladder perforation was detected by radiologic study. Urgent laparotomy was performed and she subsequently underwent cholecystectomy and drain insertion. Postoperative septic shock developed and she died due to multiple organ dysfunction syndrome. The determined diagnosis was described as gallbladder wall perforation associated with Burkitt's lymphoma infiltration in the pathology report. It is very important for the clinicians to take into the consideration that a rare cause of gallbladder perforation is Burkitt's lymphoma and it has an aggressive postoperative clinical course.
\end{abstract}

Keywords: Gallbladder perforation, Burkitt's lymphoma

Received: June 8, 2018; Accepted: January 29, 2019; Published Online: July 21, 2019

G allbladder perforation is a rare but life-threatening condition. Acute cholecystitis may be seen in $2-15 \%$ of the patients and it is usually observed with gallbladder stones $[1,2]$. Although gallbladder perforation has been uncommonly seen, mortality is high with a rate of $12-42 \%[1,3,4]$. Thus, it is very important to establish an early diagnosis and immediate medical treatment.

The associating illnesses in the patients with gallbladder stone disease predispose the development of gallbladder perforation. In immunocompromised patients, when the cholecystitis cannot be contained the disease may progress causing perforation. Besides, the diseases involve the gallbladder wall may also cause perforation. In this case report, we aim to scrutinize the gallbladder perforation developed secondary to Burkitt's lymphoma which both impairing the immune system and infiltrating the gallbladder wall and also to share this case illustrating a sample that is not described in the literature so far.

\section{CASE PRESENTATION}

A 68-year-old woman was admitted to our orthopedic clinic with the complaints of pain in her left arm. Since no fractures has been identified in her initial examination, she was referred to infectious

Address for correspondence: Musa Zorlu, MD., Private Active Hospital, Department of General Surgery, Yalova, Turkey

E-mail:mzorlu@hotmail.com 
diseases department with the pre-diagnosis of liver cirrhosis process based on anti-HCV $(+)$, leukocytosis, elevated sedimentation, and thrombocytopenia findings. Patient was hospitalized for further examinations and treatment. In her anamnesis, she reported appetite loss, night sweats, weight loss, and fever. She had no specific past medical history but hypertension. During her hospitalization, no significant clinical manifestation has been found with the exception of slight hyperemia in the upper inner (superomedial) quadrant of the left breast and edema in the left upper extremity.

Upper extremity venous color doppler Ultrasonography showed thick, heterogeneous, and edematous tissue layer under the skin surface and multiple lymphadenopathies (maximum $25 \times 26 \mathrm{~mm}$ in diameter). Furthermore, presence of lymphadenopathies in the left supraclavicular region and edema caused pressure on the left subclavian and axillary arteries have also been detected.

Abdominal ultrasonography showed gallbladder wall thickness of $10 \mathrm{~mm}$ and edematous appearance (cholecystitis). Deformation on gallbladder lateral walls was observed and found to be equivocal with respect to gallbladder perforation. Hypoechoic images were observed in the gallbladder, with the largest of which was matching with a $1 \mathrm{~mm}$ stone. Abdominal Computed Tomography (CT) showed increased gallbladder distention and wall thickening, and also fluid collection in the pericholecystic area (acute cholecystitis). A collection area of $2.5 \times 2 \mathrm{~cm}$ has been detected on the gallbladder lateral walls between the gallbladder and the liver. Poorly defined gallbladder walls have been noted (perforation). There were large numbers of lymph nodes in the paraaortic region none of which regarded as pathological (Figure 1). Thoracic CT showed diffuse thickness on the left thoracic wall and beneath the skin surface of the left breast, and increased density (abscess? or hematoma?).

The patient was administrated with $4 \times 1$ gr of ampicillin sulbactam for the cellulitis in her left breast. Hematology consultation was made when the thrombocyte level decreased from 40,000 to 19,000. Since Burkitt's-like cells had been observed in the peripheral smear, the patient was pre-diagnosed with acute lymphocytic leulemia (ALL) or lymphoma. Lymph node excisional biopsy and bone marrow biopsy were planned for the patient. Meanwhile, general surgery consultation was requested since she manifested acute abdomen clinical table.

After the general surgery consultation; the results were evaluated as follows; her general condition was poor, body temperature was $37.5^{\circ} \mathrm{C},\left(99.5^{\circ} \mathrm{F}\right)$, had a positive Murphy's sign, and there was sensitivity in the other quadrants of the abdomen but no muscular defance. As a result of patient's clinical and radiologic evaluation, she was transferred into general surgery clinic for emergency laparotomy with the diagnosis of lymphoma? + ALL? Preoperative fluid resuscitation, antibiotherapy, and thrombocyte replacement were performed. Patient, whose anesthetic risk reported as ASA IV E, underwent an emergency laparotomy. Exploration revealed that gallbladder wall at the liver side was perforated and abscesses formed in the intraparenchymal area. Open cholecystectomy + debridement + drainage processes were applied.

Thrombocyte apheresis and erythrocyte replacement were performed during and after the surgery. In the first preoperative day, general condition of the patient worsened and hemorrhagic exudate leaving the drains and incision lines were observed. The patient had $38.5^{\circ} \mathrm{C}\left(101.3{ }^{\circ} \mathrm{F}\right)$ fever, oliguria, hypotension, tachycardia, and tachypnea, then she also had septic shock and subsequently multiple organ dysfunction syndrome. The patient not responding to resuscitative interventions died. Morphological and immunohistochemical findings of the case are "Burkitt's lymphoma".

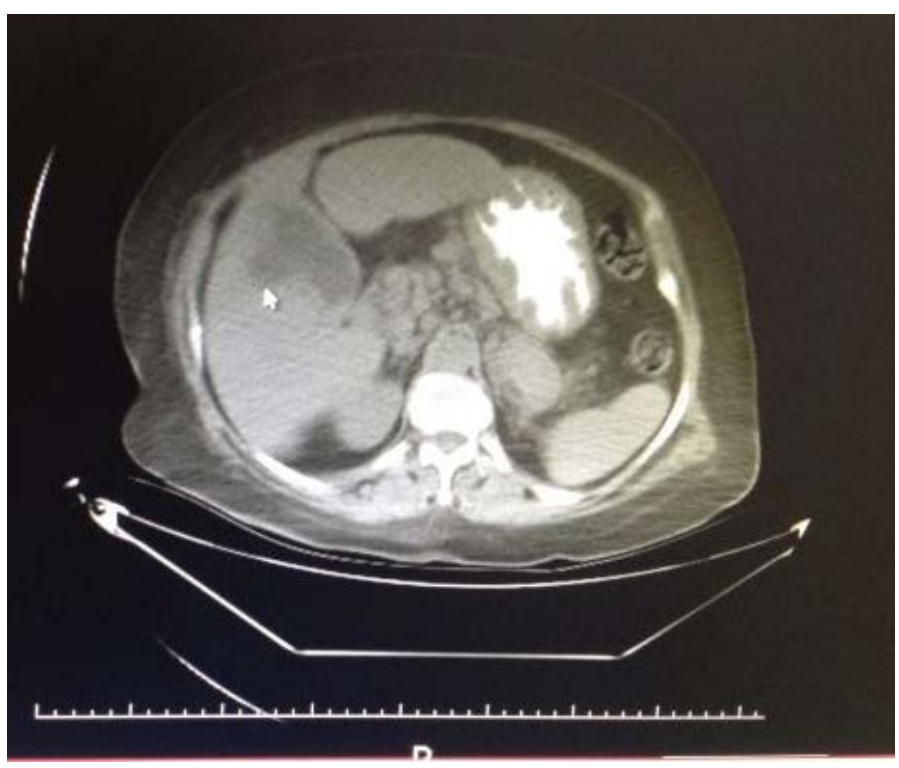

Figure 1. Gallbladder perforation area. 


\section{DISCUSSION}

Gallbladder perforation is an uncommon but lifethreatening condition. Sometimes it may not be differentiated from uncomplicated acute cholecystitis and may result in morbidity and mortality due to delayed diagnosis $[1,2]$. While gallbladder perforation rate could be seen as $2-15 \%$ in the patients with acute cholecystitis, this rate was observed between 3.3-5.9\% when evaluated along with acute and chronic gallbladder perforations [3-5].

According to Neimer classification, gallbladder perforation divides into three subtypes. Type- 1 is called acute free perforation and associated with generalized biliary peritonitis. Type- 2 is called subacute pericholecystic abscess and associated with peritonitis. Type-3 is called chronic cholecystoenteric fistulation and associated with fistula [6]. The appearances of these types are different from each other. Type- 1 patients are usually immune impaired thus, the disease cannot be localized and consequently lead to free perforation and generalized peritonitis. While Type- 2 patients are monitored in subacute care clinics, Type-3 patients develop chronic cholecystitis and it is very difficult to diagnose unless they present with obstructive hepatitis symptoms $[2,3]$. In the pathological analysis of this case, it has been considered that; Type-2 perforation was developed due to Burkitt's lymphoma infiltration into gallbladder wall, and also as secondary to immune insufficiency caused by Burkitt's lymphoma and probable bone marrow suppression, disease could not be controlled and the prognosis rapidly progressed into multiple organ dysfunction syndrome.

Gallbladder perforation may occur within the 24 hours after acute cholecystitis, as well it may develop in between a couple of days and weeks [7]. It is not possible to predict in which patient gallbladder perforation will develop [2, 3, 8]. Prognostic risk factors such as older age, male gender, associating illnesses, fever 380C (100.4 0F), elevated white blood cell (WBC) count may indicate the patients in whom the complications such as gangrene, empyema, emphysematous cholecystitis, and perforation could occur $[9,10]$.

Some associate systemic diseases such as atherosclerotic heart disease, diabetes among these prognostic risk factors may induce ischemia of the gallbladder wall, causing to necrosis and perforation $[1,3]$. Furthermore, in the medical conditions where immune system is suppressed, the disease may also progress leading to perforation. In this case report, 68 years-old patient's higher age group, Burkitt's lymphoma and hypertension as associating illnesses, fever $>37.5^{\circ} \mathrm{C}\left(99.5^{\circ} \mathrm{F}\right), \mathrm{WBC}$ of $17.3109 / \mathrm{L}$ are all matching with the literature in terms of the risk factors. It has been thought that these risk factors led to gallbladder perforation.

It is very difficult to preoperatively diagnose gallbladder perforation. Perforation of the gallbladder wall appears as defect on abdominal ultrasonography, furthermore abdominal CT contributed to increasing the accuracy in diagnosis [8]. Once the gallbladder perforation was diagnosed, it is of most importance that an immediate surgical intervention should be performed for diminishing morbidity and mortality [2]. In this case, gallbladder perforation was accurately diagnosed with both abdominal ultrasonography and abdominal CT and immediate laparotomy was performed.

One of the diseases, which cause to immune system impairing, is Burkitt's lymphoma. Burkitt's lymphoma is a disease, which starts in B-cells, aggressively progressing and developing a course with leukemia and extranodal involvement [11]. It has a low incidence of occurring in the adults [12]. Its incidence is $0.3 / 100.000$ in US [13]. Appetite loss, night sweats, weight loss and fever symptoms present in the clinical table of Burkitt's lymphoma. Our patient had also presented appetite loss, night sweats, weight loss and fever at the time of admittance. So BL's stage accepted stage4B because of organ infiltration (gallbladder) and probable bone marrow infiltration (thrombocytopenia).

In the classification, there are three types of Burkitt's lymphoma: endemic, sporadic, and immunodeficiency-associated. While the endemic variant usually observed as tumors of the Jaw, sporadic type seen in the abdomen [14]. In our country Burkitt's lymphoma occurs mainly with abdominal diseases $(70 \%)$ then with the involvement of orbit and jaw (45\%) [15-18]. Although sporadic Burkitt's lymphoma is rarely seen in adults, it has an aggressive prognosis. Involvement of the gastrointestinal system is typical and it occurs most commonly in the ileocecal region, rarely seen in stomach or duodenum primarily. 
$[19,20]$.

Common clinical presentations of Burkitt's lymphoma include intestinal obstruction and intussusception [21]. Liver, spleen, bone marrow, central nervous system; and less commonly skin, eyes, thyroid, bones, breasts and gonads are the regions where extranodal involvement occurs [22]. In literature, Burkitt's lymphoma coexisting in gallbladder and rectum has been reported only for an 11-year-old boy and it was presented as an unusual case [23]. Extranodal site of involvement of Burkitt's lymphoma was also gallbladder in that case.

Acute phase reactants such as sedimentation rates, C-reactive protein and procalcitonin levels found to be elevated in the biochemical blood analysis and hemogram testings. Expected high levels of lactate dehydrogenase and elevated uric acid levels in most patients with Burkitt's lymphoma were also measured greater than the reference ranges in this case. High levels of tumor markers were measured. Furthermore, it has been thought that the presence of thrombocytopenia in hemogram analysis and post-

Table 1. Laboratory results of the patient in admission, pre- and postoperative periods

\begin{tabular}{|c|c|c|c|}
\hline & Admission & Preoperative & Postoperative \\
\hline White blood cells $\left(4-1010^{9} / \mathrm{L}\right)$ & 11.5 & 17.3 & 25.1 \\
\hline Hemoglobin $(3.5-5 \mathrm{gr} / \mathrm{dl})$ & 11.5 & 13.7 & 10.3 \\
\hline Hematocrit (34-47 \%) & 33.6 & 29.5 & 41 \\
\hline Platelets (110-300 10\%/L) & 40.000 & 53.000 & 83.000 \\
\hline $\mathrm{CRP}(0-5 \mathrm{mg} / \mathrm{L})$ & 216 & - & - \\
\hline Sedimentation $(1-20 \mathrm{~mm} / \mathrm{h})$ & 70 & - & - \\
\hline Procalcitonin $(0-0.046$ ng/dl) & 0,92 & - & - \\
\hline Anti HCV (0-1 COI) & + & + & + \\
\hline HCV RNA & Negative & Negative & Negative \\
\hline Anti-HBs (2-10 IU/L) & $<2$ & $<2$ & $<2$ \\
\hline Anti HIV (0-1 COI) & Negative & Negative & Negative \\
\hline HbsAg (0-1 COI) & Negative & Negative & Negative \\
\hline AST (15-37 IU/L) & 98 & 185 & 56.5 \\
\hline Urea $(15-38.5 \mathrm{mg} / \mathrm{dl})$ & 21 & 40.6 & 53.9 \\
\hline Creatinine $(0.6-1 \mathrm{mg} / \mathrm{dl})$ & 1.19 & 1.99 & 1.57 \\
\hline Total bilirubin $(0.2-1 \mathrm{mg} / \mathrm{dl})$ & 1.7 & 1.8 & 1.9 \\
\hline Direct bilirubin $(0-1.2 \mathrm{mg} / \mathrm{dl})$ & 0.4 & 0.4 & 0.19 \\
\hline LDH (5-248 U/1) & 1630 & 1850 & 2444 \\
\hline Uric acid (2.6-6 mg/dl) & 8 & 11.2 & 14.5 \\
\hline Albumin $(3.4-5 \mathrm{mg} / \mathrm{dl})$ & 2.6 & 2.41 & 2.01 \\
\hline INR (0.8-1.3) & 1,09 & 1,4 & 2.6 \\
\hline CA $19.9(0-39 \mathrm{U} / \mathrm{ml})$ & 578 & - & - \\
\hline CA $125(0-35 \mathrm{U} / \mathrm{ml})$ & 55.73 & - & - \\
\hline Blood culture & No growth & No growth & No growth \\
\hline Urea culture & No growth & No growth & No growth \\
\hline Peripheral cmear & - & Burkitt's-like cells & - \\
\hline
\end{tabular}

$\mathrm{INR}=$ international normalized rate, $\mathrm{AST}=$ aspartate aminotransferase, $\mathrm{CRP}=\mathrm{C}$-reactive protein, $\mathrm{LDH}=$ lactate dehydrogenase, $\mathrm{CA}=$ cancer antigen, $\mathrm{HCV}=$ hepatitis $\mathrm{C}$ virus, $\mathrm{RNA}=$ ribonucleic acid, $\mathrm{HbsAg}=$ hepatitis $\mathrm{B}$ surface antigen, HIV = human immunodefiency virus 
operative increase in international normalized ratio starting the bleeding diathesis caused by a probable bone marrow infiltration (Table 1).

Chemotherapy and radiation therapy are very effective in Burkitt's lymphoma treatment, while surgery is required only for the treatment of developed complications [24]. The surgical indication in this case is the development of gallbladder perforation. The development of this condition increasing the risk of mortality and morbidity has warranted an emergency laparotomy.

\section{CONCLUSION}

Gallbladder perforation is a rare disease but has a high rate of mortality and morbidity when left untreated. One of the causes of gallbladder perforation is the disorder directly infiltrating the gallbladder wall. Also in this case, Burkitt's lymphoma caused perforation by infiltrating gallbladder wall as the extranodal site of involvement. In conclusion, the clinicians should keep in mind that Burkitt's lymphoma might be a rare cause of gallbladder perforation, and also mortality and morbidity rates in the treatment period might be high depending on the magnitude of the systemic involvement.

\section{Informed consent}

Written informed consent was obtained from the patient for publication of this case report and any accompanying images.

\section{Conflict of interest}

The author declared that there are no potential conflicts of interest with respect to the research, authorship, and/or publication of this article.

\section{REFERENCES}

[1] Roslyn JJ, Thompson JE Jr, Darvin H, DenBesten L. Risk factors for gallbladder perforation. Am J Gastroenterol 1987;82:636-40.

[2] Menakuru SR, Kaman L, Behera A, Singh R, Katariya RN. Current management of gall bladder perforations. ANZ J Surg 2004;74:843-6.

[3] Derici H, Kara C, Bozdag AD, Nazli O, Tansug T, Akca E. Diagnosis and treatment of gallbladder perforation. World $\mathrm{J}$
Gastroenterol 2006;12:7832-6.

[4] Lennon F, Green WE. Perforation of the gallbladder. A review of 32 cases. J R Coll Surg Edinb 1983;28:169-73.

[5] Williams NF, Scobie TK. Perforation of the gallbladder: analysis of 19 cases. Can Med Assoc J 1976;115:1223-5.

[6] Niemeier O. Acute free perforation of the gallbladder. Ann Surg 1934;99:922-4.

[7] Alvi AR, Ajmal S, Saleem T. Acute free perforation of gall bladder encountered at initial presentation in 51 years old man: a case report. Cases J 2009;2:166.

[8] Sood BP, Kalra N, Gupta S, Sidhu R, Gulati M, Khandelwal $\mathrm{N}$, et al. Role of sonography in the diagnosis of gallbladder perforation. J Clin Ultrasound 2002;30:270-4.

[9] Gruber PJ, Silverman RA, Gottesfeld S, Flaster E. Presence of fever and leukocytosis in acute cholecystitis. Ann Emerg Med 1996;28:273-7.

[10] Merriam LT, Kanaan SA, Dawes LG, Angelos P, Prystowsky JB, Rege RV, et al. Gangrenous cholecystitis: analysis of risk factors and experience with laparoscopic cholecystectomy. Surgery 1999; $126: 680-6$.

[11] Boerma EG, van Imhoff GW, Appel IM, Veeger NJ, Kluin PM, Kluin-Nelemans JC. Gender and age-related differences in Burkitt lymphoma--epidemiological and clinical data from The Netherlands. Eur J Cancer, 2004;40:2781-7.

[12] Blum KA, Lozanski G, Byrd JC. Adult Burkitt leukemia and lymphoma. Blood 2004;104:3009-20.

[13] Morton LM, Wang SS, Devesa SS, Hartge P, Weisenburger DD, Linet MS. Lymphoma incidence patterns by WHO subtype in the United States, 1992-2001. Blood 2006;107:265-76.

[14] Ziegler JL. Burkitt's lymphoma. N Engl J Med 1981;305:735-45.

[15] Ertem U, Duru F, Pamir A, Taçyildiz N, Dağdemir A, Akçayöz A, et al. Burkitt's lymphoma in 63 Turkish children diagnosed over a 10 year period. Pediatr Hematol Oncol 1996;13:123-34.

[16] Kutluk T, Varan A, Akyüz C, Büyükpamukçu M. Clinical characteristics and treatment results of LMB/LMT regimen in children with non-Hodgkin's lymphoma. Cancer Invest 2002;20:626-33.

[17] Cavdar AO, Yavuz G, Babacan E, Gözdasoglu S, Unal E, Ertem U, et al. Burkitt's lymphoma in Turkish children: clinical, viral [EBV] and molecular studies. Leuk Lymphoma 1994;14:323-30.

[18\} Tüzüner N, Ince U, Yildiz I, Göçener S, Ulukutlu L. Small non-cleaved follicular center cell lymphoma in Turkey. Burkitt's and non-Burkitt's types. A retrospective clinicopathologic analysis of 53 cases in the pediatric age group. Cancer 1987;59:925-32.

[19] Ferry JA. Burkitt's lymphoma: clinicopathologic features and differential diagnosis. Oncologist 2006;11:375-83.

[20] Brooks JJ, Enterline HT. Primary gastric lymphomas. A clinicopathologic study of 58 cases with long-term follow-up and literature review. Cancer 1983;51:701-11.

[21] Wang SM, Huang FC, Wu CH, Ko SF, Lee SY, Hsiao CC. Ileocecal Burkitt's lymphoma presenting as ileocolic intussusception with appendiceal invagination and acute appendicitis. J Formos Med Assoc 2010;109:476-9. 
[22] Allen CE, Kamdar KY, Bollard CM, Gross TG. Malignant [Burkitt's lymphoma: atypical localization]. Rev Esp Enferm Dig non-Hodgkin lymphomas in children. In: Pizzo PA, Poplack DG, 1996;88:439-41. [Article in Spanish]

eds. Principles and Practice of Pediatric Oncology. 7th ed. [24] Watson N, Cassibba V, Casini M, Mega A, Tauber M, Iori Philadelphia Pa: Lippincott Williams \& Wilkins; 2016:587-603. A, et al. Burkitt's Lymphoma of the stomach: a case report and [23] Balonga C, Lencina R, Reus M, Garre C, de las Heras M. review of the literature. J Blood Disord 2014;1:4. 